avoid the use of dentifrices containing the detergent sodium lauryl sulphate (SLS). ${ }^{2}$

ARDEN G CHRISTEN Indiana University School of Dentistry Indianapolis, Indiana, USA

1 Christen AG, McDonald JL, Christen JA. The impact of tobacco use and cessation on nonmalignant and precancerous oral and dental diseases and conditions. Indianapolis: Indiana University School of Dentistry, 1991.

2 Harris NO, Christen AG. Primary preventive dentistry, 4th ed. Norwalk, Connecticut: Appleton and Lange, 1995: 113.

\section{Acute eosinophilic pneumonia: a new smoking related illness?}

To the Editor - Initiation of smoking begins primarily during the teenage years. The increase in the number of underage smokers and young women smoking is one of Japan's most important health problems. ${ }^{1}$ Young people may not be impressed by long term health risks such as lung cancer, chronic bronchitis, and emphysema. Recently we saw two young patients with acute eosinophilic pneumonia (AEP), which occurred just after smoking initiation. A 19 year old woman and 18 year old man, both previously healthy, were admitted to our hospital because of acute respiratory distress and diffuse pulmonary infiltrates on chest radiographs. Eosinophilic pneumonia was diagnosed by bronchoalveolar lavage and transbronchial lung biopsy. There was no evidence of an infectious aetiology. Both patients rapidly improved with corticosteroid therapy, and AEP was diagnosed by its clinical course.

Of interest is the fact that one patient had started smoking 10 days before the onset, and the other 3 days before. In the male patient, a challenge test was performed 44 days after his initial episode of AEP (two weeks after withdrawal of corticosteroids). He was asked to smoke three cigarettes in three hours Subjective symptoms, physical findings, and pulmonary function tests were assessed after smoking each cigarette. He showed dry cough, dyspnoea, and hypoxaemia $\left(\mathrm{PaO}_{2} 7.5\right.$ $\mathrm{kPa}) 15$ hours after he smoked the las cigarette. Although a chest radiograph taken at that time revealed no abnormalities, FVC, $\mathrm{FEV}_{1}$, and diffusing capacity (transfer factor) were decreased significantly. He recovered quickly again following the administration of corticosteroids.

From a review of the literature and abstracts of medical congresses, we found approximately 40 cases of AEP reported in Japan, and most of them were under 20 years old or in their early 20s. To our knowledge, there were eight other cases that suggested a relationship between smoking and onset of the disease. ${ }^{2}$ In a computer based search of the literature-using the key words "smoking" or "cigarette" and "acute eosinophilic pneumonia" in combination we were unable to find reports of a possible association between smoking and AEP.

Although AEP is a newly recognised clinical entity and a hypersensitivity reaction to inhaled antigen is suggested, ${ }^{3.4}$ no particular precipitating cause has been identified in any patient with AEP. ${ }^{5}$ It is well known that cigarette smoke is a complex mixture of more than 4000 compounds. Numerous clinical studies have documented smoking induced alterations in immune and inflammatory function. ${ }^{6}$ Cigarette smoking has also been shown to be a cause of heightened airway responsiveness.

The possibility that inhalation of cigarette smoke might play a role in the onset of AEP should be further explored. We encourage other investigators who are aware of cases of AEP to assess whether they may be related to smoking.

HIROSHI KAWANE TAKASHI SASAKI Division of Respiratory Diseases, Department of Medicine,
Kawasaki Medical School, Kurashiki City, fapan

1 Kawane $\mathrm{H}$. The influence of the US tobacco industry in foreign markets. $N$ Engl $\mathcal{F ~ M e d ~}$ 1991; 325: 815 .

2 Abstracts of Annual Congress of Japan Society of Chest Diseases, 1995.

3 Allen JN, Pacht ER, Gadek JE, Davis WB. Acute eosinophilic pneumonia as a reversal cause of noninfectious respiratory failure. $N$ Engl f Med 1989; 321 : 569-74

4 Badesch DB, King TC, Schwarz MI. Acute eosinophilic pneumonia: a hypersensitivit phenomenon? Am Rev Respir Dis 1989; 139 249-52.

5 Acute eosinophilic pneumonia. Lancet 1990; 335 : 947.

6 US Department of Health and Human Services. The health benefits of smoking cessation. US Department of Health and Human Services, Public Health Service, Centers for Disease Control, Office on Smoking and Health, 1990 (DHHS Publication No. (CDC) 90-8416.)

\section{What should we call ex-smokers?}

To the Editor - Efforts to integrate the treatment of nicotine and tobacco dependence into the mainstream of addiction treatment have been hampered by resistance on the part of physicians, treatment professionals, and their patients. Physicians want their patients who smoke to quit because smoking causes illness and premature death, but the success of standard medical methods is so poor that many, both physicians and patients, stop trying. Most addiction treatment professionals concede that nicotine and tobacco dependence should be included in addiction treatment but are unwilling to make the effort. Seventy five percent of alcoholics and other drug addicts are smokers; most state that they would be "better off" if they stopped smoking, but few are willing to acknowledge that nicotine and tobacco dependence represents an addiction similar to their other addictions.

Part of this resistance may have a semantic basis. Alcoholics refer to the state of recovery from alcoholism as being sober. Heroin and cocaine addicts refer to the state of recovery from their addictions as being clean. As yet, no equivalent term referring to the state of recovery from nicotine and tobacco dependence has received general acceptance. "Smoke-free" has been used, but it lacks the necessary emotional impact. "Clear" has been suggested by Charyn Sutton (John Slade, personal communication), but it has failed to excite interest at professional meetings or in patient groups.

We propose the phrase "clean and free" to indicate the state of recovery from nicotine and tobacco dependence. "Clean" suggests the salubrious result of quitting smoking (clean lungs, clean breath, clean ashtrays) and "free" suggests physical, emotional, and spiritual freedom from being controlled by an addicting substance. "Clean" has been the primary focus of public health pro- fessionals and physicians, while "free" has been the focus of addiction treatment professionals, psychologists, and psychotherapists. Placed together, "clean and free" unites the two concepts and the two treatment goals.

We hope others will explore the use of the phrase "clean and free" as a term to indicate the state of recovery from nicotine and tobacco dependence, and will report on its acceptance among various groups.

$$
\begin{array}{r}
\text { TERRY A RUSTIN } \\
\text { University of Texas Medical School at Houston } \\
\text { Houston, Texas, USA } \\
\text { TIMOTHY MCINDOO } \\
\text { Hazelden Foundation } \\
\text { Center City, Minnesota, USA }
\end{array}
$$

In reply - The above letter generated animated discussion among the editors. We have strong doubts about the validity of the authors' central proposition ("Part of this resistance [in smokers to acknowledge nicotine addiction] may have a semantic basis.") and about their statement that "few [smokers] are willing to acknowledge that nicotine and tobacco dependence represents an addiction similar to their other addictions." Kozlowski and colleagues have shown that polydrug users generally repor an intensity of desire for cigarettes when they are unavailable that is as high or higher than for heroin, cocaine, or alcohol when the latter are not available. ${ }^{1}$ Moreover, public opinion polls have consistently shown that a large majority of smokers consider cigarettes to be addicting - for example, $91 \%$ of current smokers and $87 \%$ of former smokers in the USA according to a 1994 New York Times/ CBS News poll. ${ }^{2}$

We are somewhat baffled by the suggestion that smokers lack a lexicon of meaningful ways of describing their having quit. We peeled off dozens of these (for example, I'm an ex-smoker; I don't smoke any more; ... since I finally stopped smoking) and wondered why the authors seemed to think it necessary or even desirable to somehow standardise the way former smokers speak about their past smoking. While some words about alcohol and other drug sobriety are part of the standard parlance of different therapeutic movements such as Alcoholics Anonymous, these are not representative of former drug users at large, where, as with exsmokers, a large proportion have stopped without recourse to formal therapies.

Finally several of us felt that "clean and free" was redolent with quasi-religious overtones that many would find alienating and unnecessarily melodramatic, perhaps fuelling community perceptions about ex-smokers being tedious "converts" preoccupied with their sinful past. We would welcome further correspondence on the wisdom of the authors' suggestion.

\section{SIMON CHAPMAN} Deputy Editor

1 Kozlowski LT, Wilkinson A, Skinner W, Kent C, Franklin T, Pope M. Comparing tobacco cigarette dependence with other drug dependencies : greater or equal "difficulty quitting", and "urges to use," but less "pleasure" from cigarettes. F $A M A$ 1989; $261: 896-901$

2 Janofsky $M$. Majority of Americans say cigarettes spur addiction. New York Times 1994; 1 May, section 2: 22 .

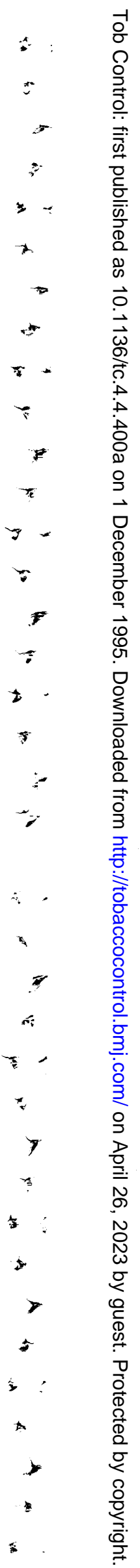

A 